\title{
Longitudinal study on factors affecting assertiveness among preceptors of novice nurses
}

\author{
Sachie TOMITA \\ Departments of Nursing, Faculty of Health \& Medical Care \\ Saitama Medical University \\ Saitama, Japan \\ tomitas@saitama-med.ac.jp \\ Hiromi YOKOYAMA \\ Departments of Nursing, Faculty of Health \& Medical Care \\ Saitama Medical University \\ Saitama, Japan \\ yoko_h@saitama-med.ac.jp \\ Kyoko CHIBA \\ Departments of Nursing, Faculty of Health \& Medical Care \\ Saitama Medical University \\ Saitama, Japan \\ chiba@saitama-med.ac.jp
}

\begin{abstract}
Purpose: This study aims to understand the assertiveness of preceptors of novice nurses and factors affecting the assertiveness through a longitudinal perspective. Methods: Anonymous self-rating questionnaire surveys were administered to 1292 preceptors working in participating city and university hospitals across Japan (August, 2013 (baseline) and March, 2014 (second survey)). The surveys had question items from the Japanese version of the Rathus Assertiveness Schedule (J-RAS, 30 items), demographic details of the participants, evaluation of novice nurses by preceptors, instruction framework, selfevaluation of preceptors, working environment, and a burnout inventory (Japanese version of the Maslach Burnout InventoryHuman Services Survey, 22 items). Bivariate analyses (T-tests and one-way analysis of variance) were conducted using assertiveness of the second survey as the objective variable, and other items of the baseline survey as explanatory variables. Selecting variables with $p$ values smaller than 0.2 obtained in the bivariate analysis as explanatory variables, a multiple linear regression analysis (Stepwise method) was conducted. For the analyses, we used a statistics analysis software, SPSS Statistic 22. Results: Choosing 836 valid respondents of the baseline survey as a cohort group, we repeated the survey 8 months after the baseline survey to identify the factors affecting the assertiveness of preceptors of novice nurses. Excluding 62 who had missing values in the question items for assertiveness, 472 participants who were followed were included in analyses. As the results, following factors were found to affect the assertiveness: thinking that 'they make rapid decisions', and that 'they are valuable as others'. Further, participants who have higher total burnout scores had lower assertiveness. Adjusted coefficient of determination was 0.153 . Discussion: It can be inferred that the assertiveness of preceptors is higher than that of novice nurses measured by the J-RAS used in this study, and lower than that of administrative nurses. The assertiveness of preceptors was higher among participants who evaluated themselves positively, thinking
\end{abstract}

\author{
Takae MACHIDA \\ Departments of Nursing, Faculty of Health \& Medical Care \\ Saitama Medical University \\ Saitama, Japan \\ t_machi@saitama-med.ac.jp
}

Saori NAKAZAWA

Departments of Nursing, Faculty of Health \& Medical Care aitama Medical University

Saitama, Japan

sao1104ringo@yahoo.co.jp

Eiko SUZUKI

Department of Nursing

International University of Health and Welfare

Tokyo, Japan

eikosuzuki@iuhw.ac.jp

that 'they make rapid decisions', and that 'they are valuable as others'. It was also found that higher 'total burnout scores' was a factor that lowers the assertiveness. These findings suggest that a positive self-evaluation improves assertiveness and helps to prevent burnout. study

Keywords; novice nurses; preceptors; assertiveness; cohort

\section{INTRODUCTION}

In Japan, senior nurses in the role of preceptors provide educational support for novice nurses to alleviate the "reality shock" of novice nurses and to assist them in adapting to the workplace. The preceptor involvement with novice nurses is important to prevent turnover and in the training of the novice nurses [1]. However, studies have reported that preceptors find this role stressful and that they are without confidence in the nursing practices and instruction they provide [2-4], and also that they may develop feelings of burnout while feeling anxieties and pressure at not knowing how to communicate with the novice nurses [5-7]. These suggest that preceptors suffer from difficulties in endeavoring to communicate with novice nurses with a kindhearted understanding attitude.

With this background, we focused on assertiveness as a self-assertive attitude, which is a communication skill in the everyday work of preceptors who are involved with novice nurses. Suzuki et al. showed that assertiveness makes coping with stress possible, and that acquiring and using assertive communication skills improve personal relations and alleviate feelings of stress [8]. As described above, previous studies have reported that assertive communication skills have been utilized in different clinical settings, and helped nurses

We declare that we have no conflicts of interest. 
establish good personal relations in the workplace, improve mental health, and prevent burnout [7, 9 -12].

A previous study that investigated the assertiveness of preceptors showed factors related to the assertiveness of preceptors who were involved with novice nurses three months after starting employment [5]. According to that study, factors related to higher assertiveness of the preceptors are to have superiors to consult with about the instruction of the novice nurses, and the preceptors accepting themselves positively. Factors related to lower assertiveness arise when being troubled and worrying about providing the instruction as well as displaying tendencies to develop burnout. However, it can be inferred that difficulties in giving instruction will reduce as novice nurses are adapting themselves to the workplace [4]. The study here was unable to locate longitudinal studies that reported factors affecting the assertiveness of preceptors of novice nurses.

From these reasons, this study aims to understand the assertiveness of preceptors of novice nurses and factors affecting the assertiveness. With a better understanding of the factors affecting the assertiveness, it is possible to draw up more detailed support and measures to improve the assertiveness of preceptors such as holding workshops, and facilitating improvements in the relationships between preceptors and novice nurses, promoting the growth and development of both parties.

\section{A. Purpose}

This study aims to understand the assertiveness of preceptors of novice nurses and factors affecting the assertiveness through a longitudinal perspective.

\section{B. Definitions of terms}

1) Preceptors: nurses who are in charge of novice nurses who started working in a ward for the first time after the completion of basic nursing education courses.

2) Assertiveness: this study uses the definition by Alberti, et al., "assertiveness is a communication skill to express oneself without specific efforts based on protecting one's own rights while respecting the rights of others" [13].

\section{METHODS}

\section{A. Study design}

Longitudinal study (prospective cohort study) and quantitative descriptive study

\section{B. Conceptual framework and details covered in this study}

We conducted the study according to the following procedures to ensure the validity of the factors related to the assertiveness of preceptors of novice nurses. The explanatory variables showing association with the assertiveness of preceptors were chosen to consider confounding factors reported in previous studies which analyzed factors related to the assertiveness of nurses and preceptors. The main variables include sex, age, years of clinical experience, experience of assertiveness training, persons to consult with, workload, stress conditions such as burnout, and self-assurance including confidence.

Also, for variables not chosen from previous studies, based on the experience of researchers and the brainstorming by faculty members of graduate schools who are familiar with studies of the assertiveness of nurses, nurses involved in instruction of novice nurses in clinical settings, and graduate students majoring in nursing management studies, we assumed that the assertiveness is related to the ways the other person evaluates interchanges. Therefore, we chose explanatory variables related to the evaluation of novice nurses by preceptors, and the instruction framework for novice nurses including team collaboration based on the changes in the instruction framework for novice nurses [14].

In total we chose 51 explanatory variables and classified them by similarity of content: 9 items of personal factors, 4 for instruction frameworks for novice nurses, 4 for evaluation of novice nurses by preceptors, 6 for self-evaluations of preceptors, 5 for environmental factors, and 24 for stress conditions including the burnout scale (MBI, 23 items). In this procedure, we established a conceptual framework using the variables chosen as explanatory variables and the total score of the assertiveness (J-RAS, 30 items) as the objective variable to verify the hypothesis. We also refined the accuracy of the question items through a pilot study with 25 preceptors, for the purpose of examining the comprehensibility and emergence order of the question items.

\section{Participants and procedures}

We communicated a request for cooperation in the study to nursing directors of hospitals in hospital listings for Japan for cooperation. The request was made in writing and orally. The inclusion criteria were for city and university hospitals with 300 or more beds and we obtained offers of cooperation from 37 hospitals. The prospective participants were 1292 nurse preceptors in charge of instructing novice nurses at the participating hospitals. The survey was with an anonymous self-rating questionnaire conducted by mail in August, 2013 (baseline) and March, 2014 (second survey).

\section{Survey items}

1) Assertiveness: The questionnaire included the Japanese version of the Rathus Assertiveness Schedule (J-RAS) to measure assertiveness, comprised of 30 question items with a score range between -90 and +90 . A higher score suggests a better ability to express opinions. The J-RAS was developed by Suzuki et al., and its validity has been established $[15,16]$. As a result of a factor analysis of the participants here, seven factors were extracted as in Suzuki et al. [4], and the Cronbach $\alpha$ coefficient was .80 . We obtained permission from Suzuki et al. to include the J-RAS in the questionnaire.

2) Demographic details (10 items): sex, age, years of clinical experience, years of preceptor experience, years of experience working in wards, position, final education, marital status, participation in academic meetings and workshops, experience of assertiveness training. 
3) Instruction framework for novice nurses (4 items): Form of instruction given to novice nurses, position in the instruction arrangements, evaluation of team collaboration in the novice nurse instruction (4-point scale, 'None' = 1 to 'A lot' $=4$ ), and number of training sessions required for instructing novice nurses (Never, 1 or 2 , or more).

4) Evaluations of novice nurses by the preceptors (4 items): novice nurses are obedient, mentally weak, with poor skills, good relationship to communicate with novice nurses, and feeling it troublesome and with worries at giving instruction. Answers on a visual analog scale (VAS): 'None' at $0 \mathrm{~mm}$ to 'A lot' at $100 \mathrm{~mm}$.

5) Self-evaluations of the preceptors (6 items): Thinking myself to be as valuable as others, making decisions based on own experience, making decisions after collecting information, making rapid decisions, having confidence in nursing practices, and thinking it worth instructing novice nurses. The responses were expressed in VAS.

6) Working environment (4 items): Workload (4-point scale; 'Very low', 'Low', 'High', 'Very high'), Overtime/week (None, $1-3$ hours, 4 hours or more), having persons to consult with about instructing novice nurses (yes/no). Satisfaction with the workplace, and collaboration with other staff scored in VAS.

7) Burnout: We used the Japanese version of the Maslach Burnout Inventory-Human Services Survey (MBI-HSS)(22 items) [17], and obtained permission to use the MBI-HSS from the developer of the Japanese version.

\section{E. Analysis}

Choosing 836 valid respondents of the baseline survey as a cohort group, we repeated the survey 8 months after the baseline survey to identify the factors affecting the assertiveness of preceptors of novice nurses. The two sets of data were matched by the dates of birth of the participants and their mothers.

1) Analysis of factors affecting to the assertiveness of preceptors: For the total score of assertiveness and demographic details of preceptors (characteristics, matters related to instruction for novice nurses, self-evaluation of preceptors, working environment, and the burnout inventory), we calculated descriptive statistics values, and performed bivariate analyses (t-tests and one-way analysis of variance). We examined the relationship between assertiveness and the total burnout score and continuous VAS variable scores by Pearson's Correlation Coefficient.

2) Multiple linear regression analysis (Stepwise method): We conducted a multiple linear regression analysis selecting variables with $\mathrm{p}$ values smaller than 0.2 from a bivariate analysis as explanatory variables and using the total score of the assertiveness as the objective variable. Confirming the multicollinearity between explanatory variables, we deleted one of the items, with a correlation coefficient that was 0.9 or above. Multicollinearity was determined for Variance Inflation Factor (VIF) values of 10 or lower for all variables. The nominal and the ordinal scales were converted into binary variables. Continuous variables were input to the multiple regression analysis as continuous variables. For the analyses, we used a statistics analysis software, SPSS Statistic 22, and set the significance level as $p<0.05$.

\section{F. Ethical considerations}

We obtained approval to conduct the study from the Ethics Committee of A University (No. 13-67). The explanatory leaflet distributed to potential participants clearly stated that participation is voluntary, and that there would be no disadvantages created by not participating, the statistical data would be anonymously processed, the completed questionnaires and data would be maintained in a secure locked location, and submission of the questionnaire would be regarded as consent to participate in the study.

\section{RESULTS}

\section{A. Participants in the cohort group}

We used 836 valid respondents of the baseline survey as a cohort group, and surveyed these participants 8 months after the baseline survey to identify the factors affecting the assertiveness of preceptors of novice nurses. The two sets of data were matched by the dates of birth of the participants and their mothers. Finally, the number of participants who were followed was 472 excluding 62 who had missing values in the question items for assertiveness.

\section{B. Results of the survey}

1) Demographic details of the participants (Tables 1, 2, 3): Tables 1 through 3 show the results of the descriptive statistics: the demographic details, mean values of the total score for assertiveness, and the standard deviations. The mean score for assertiveness of the 472 participants was $-10.15 \pm$ 18.25. The mean age was $30.3 \pm 6.17$ years, and participants older than 32 accounted for $30 \%$ of the total. The mean length of clinical experience was $7.5 \pm 5.36$ years, and for those with experience for 2 to 3.9 years, and 4 to 5.9 years, each accounted for $30 \%$. About $30 \%$ of the participants had more than 10 years of clinical experience. The mean length of experience in the present ward was $3.9 \pm 2.56$ years, and about $40 \%$ reported 2 to 3.9 years of experience in the present ward. The mean length of preceptor experience was 2.14 ( \pm 3.11$)$ years.

2) Bivariate analyses: Tables 1 through 3 show the relationship between the variables of the cohort group and assertiveness analyzed based on the personal factors, instruction frameworks for novice nurses, the evaluation of novice nurses by preceptors, self-evaluations of preceptors, environmental factors, and stress conditions. 
Table 1 Mean total score of assertiveness by participant characteristics (1) $\quad N=472$

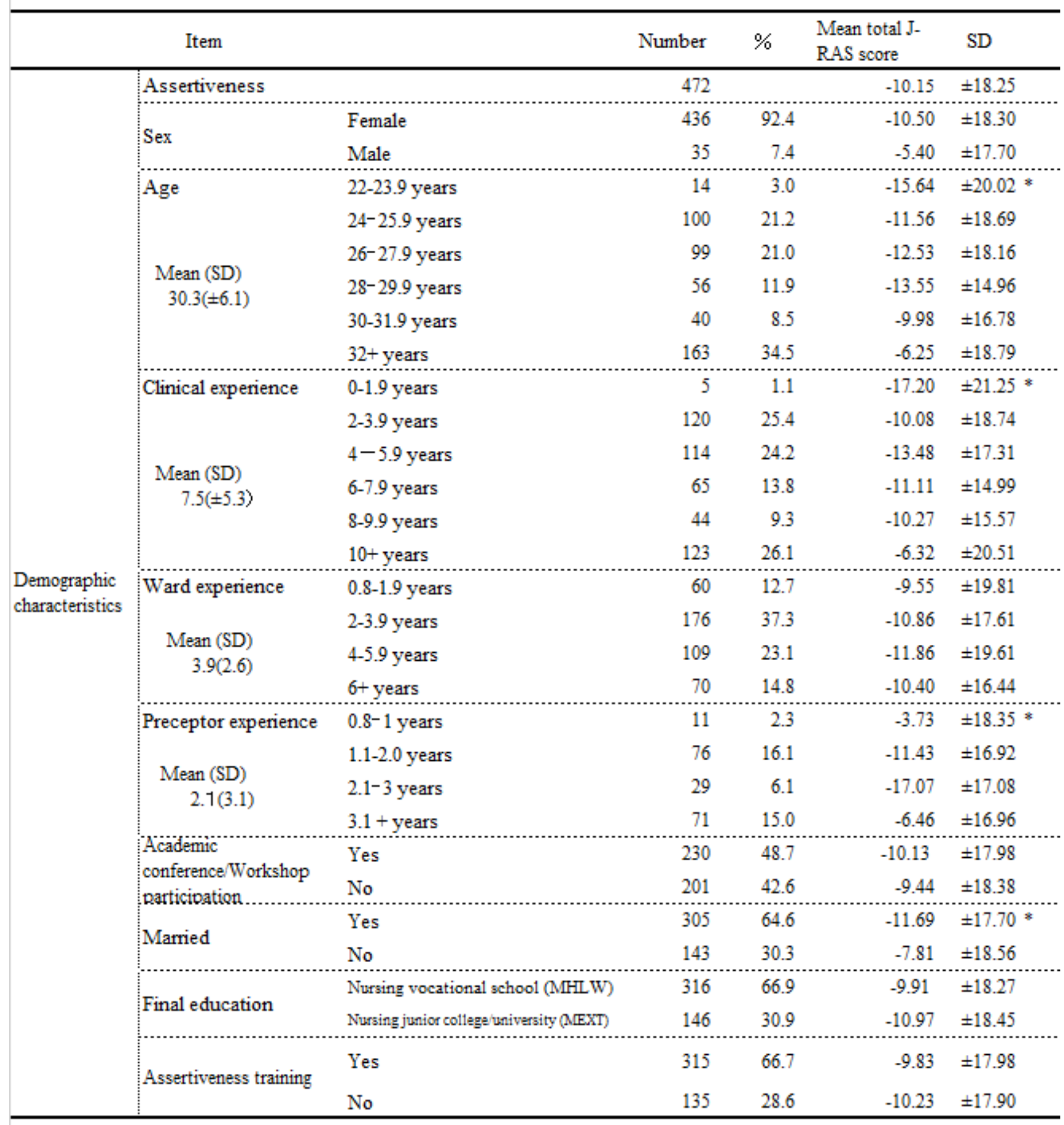

one-way analysis of variance for 3 groups, t-tests for 2 groups $*: p<0.05 * *$ p $<0.01 \quad \dagger<0.2$

MHLW: Ministry of Health, Labor and Welfare of Japan

MEXT: Ministry of Education, Culture, Sports, Science and Technology of Japan 
Table 2 Mean total assertiveness score by participant characteristics (2) $N=472$

\begin{tabular}{|c|c|c|c|c|c|c|c|}
\hline & Item & & & Number & $\%$ & $\begin{array}{l}\text { Mean total } \\
\text { J-RAS score }\end{array}$ & $\mathrm{SD}$ \\
\hline \multirow{12}{*}{ Instruction } & \multirow{2}{*}{ Type } & Team & & 294 & 62.3 & -10.02 & \pm 18.26 \\
\hline & & One-to-one & & 163 & 34.5 & -10.71 & \pm 18.70 \\
\hline & \multirow{4}{*}{ Team collaboration } & None & & 3 & 0.6 & -23.00 & $\pm 15.62 *$ \\
\hline & & Very little & & 83 & 17.6 & -11.95 & \pm 17.04 \\
\hline & & Some & & 259 & 54.9 & -10.30 & \pm 18.11 \\
\hline & & A lot & & 121 & 25.6 & -8.56 & \pm 19.47 \\
\hline & \multirow{3}{*}{ Instructor } & Instructor & & 360 & 76.3 & -10.91 & $\pm 17.73 *$ \\
\hline & & Leader preceptor & & 69 & 14.6 & -9.30 & \pm 18.25 \\
\hline & & Senior & & 20 & 4.2 & -5.00 & \pm 23.10 \\
\hline & \multirow{3}{*}{$\begin{array}{l}\text { Preceptor training } \\
\text { (times) }\end{array}$} & None & & 45 & 9.5 & -8.22 & \pm 18.28 \\
\hline & & Once or twice & & 268 & 56.8 & -10.69 & \pm 19.21 \\
\hline & & 3 or more times & & 155 & 32.8 & -9.53 & \pm 16.63 \\
\hline \multirow{21}{*}{$\begin{array}{l}\text { Working } \\
\text { environment }\end{array}$} & \multirow{14}{*}{ Consults with } & \multirow[t]{2}{*}{ Head of education } & Yes & 269 & 57.0 & -10.01 & -10.01 \\
\hline & & & No & 203 & 43.0 & -10.34 & -10.34 \\
\hline & & \multirow[t]{2}{*}{ Other preceptor } & Yes & 327 & 69.3 & -10.28 & -10.28 \\
\hline & & & No & 145 & 30.7 & -9.86 & -9.86 \\
\hline & & \multirow[t]{2}{*}{ Trainer } & Yes & 30 & 6.4 & -5.33 & $-5.33 \dagger$ \\
\hline & & & No & 442 & 93.6 & -10.48 & -10.48 \\
\hline & & \multirow[t]{2}{*}{ Senior, not trainer } & Yes & 127 & 26.9 & -12.81 & $-12.81 \dagger$ \\
\hline & & & No & 345 & 73.1 & -9.17 & -9.17 \\
\hline & & \multirow[t]{2}{*}{ Superior } & Yes & 270 & 57.2 & -8.67 & $-8.67 *$ \\
\hline & & & No & 202 & 42.8 & -12.13 & -12.13 \\
\hline & & \multirow[t]{2}{*}{ Peer } & Yes & 323 & 68.4 & -9.39 & $-9.39 \dagger$ \\
\hline & & & No & 149 & 31.6 & -11.81 & -11.81 \\
\hline & & \multirow[t]{2}{*}{ Staff of different workplace } & Yes & 127 & 26.9 & -8.73 & -8.73 \\
\hline & & & No & 345 & 73.1 & -10.68 & -10.68 \\
\hline & \multirow{4}{*}{ Workload } & Very low & & 3 & 0.6 & -35.67 & $-35.67+$ \\
\hline & & Low & & 16 & 3.4 & -9.63 & -9.63 \\
\hline & & High & & 264 & 55.9 & -9.94 & -9.94 \\
\hline & & Very high & & 186 & 39.4 & -10.10 & -10.1 \\
\hline & \multirow{3}{*}{ Overtime (hours) } & None & & 22 & 4.66 & -3.86 & $-386 \%$ \\
\hline & & $1-3$ hours & & 200 & 42.4 & -9.25 & -9.25 \\
\hline & & $4+$ hours & & 249 & 52.8 & -11.10 & -11.1 \\
\hline
\end{tabular}

a) Personal factors and assertiveness (Table 1): There were significant differences in gender, age, years of experience, years of preceptor experience, and marital status $(p<.05)$. A statistically significantly higher assertiveness was found in the following preceptors: those aged 32 and older (vs. the 22-23.9, and 28-29.9 year groups), 10 years and longer clinical experience (vs. 1.9 years or shorter), 3.1 years and longer preceptor experience (vs. 2.1-3.0 years), and single (vs. married $)(p<.05)$. b) Instruction framework for novice nurses and assertiveness: Statistically significantly higher assertiveness was found in the following preceptors: thinking that team collaboration is good, and higher age of the instructor (preceptor) as better $(p<.05)$. 
Table 3 Correlations between continuous variables and assertiveness scores $\quad \mathrm{N}=472$

\begin{tabular}{|c|c|c|c|c|}
\hline & & Mean & SD & correlation coefficient \\
\hline \multirow{4}{*}{$\begin{array}{l}\text { Evaluations } \\
\text { of novice } \\
\text { nurses by the } \\
\text { preceptors }\end{array}$} & Obedient & 67.84 & \pm 24.23 & 0.07 \\
\hline & Mentally weak & 59.69 & \pm 24.81 & 0.04 \\
\hline & With poor skills & 68.64 & \pm 20.96 & $0.11 *$ \\
\hline & Good relationship to communicate with novice nurses & 58.19 & \pm 19.96 & $0.12 * *$ \\
\hline \multirow{7}{*}{$\begin{array}{l}\text { Self- } \\
\text { evaluations of } \\
\text { the } \\
\text { preceptors }\end{array}$} & Thinking it worth instructing novice nurses & 53.01 & \pm 19.47 & $0.19 * *$ \\
\hline & Finding instruction troublesome & 69.21 & \pm 21.60 & -0.05 \\
\hline & Thinking my self to be as valuable as others & 49.86 & \pm 20.48 & $0.32 * *$ \\
\hline & Making decisions based on own experience & 65.94 & \pm 15.87 & 0.07 \\
\hline & Making decisions after collecting information & 68.03 & \pm 15.72 & 0.09 \\
\hline & Making rapid decisions & 49.14 & \pm 20.26 & $0 . .31 * *$ \\
\hline & Having confidence in the nursing at the present workplace & 47.74 & \pm 19.35 & $0.31 * *$ \\
\hline \multirow{2}{*}{$\begin{array}{l}\text { Working } \\
\text { environment }\end{array}$} & Satisfaction with the workplace & 49.53 & \pm 23.88 & $0.147 * *$ \\
\hline & Collaborating with other professionals & 59.65 & \pm 20.57 & $0.188 * *$ \\
\hline Burnout & Total burnout score & 11.34 & \pm 2.00 & $-0.34 * *$ \\
\hline
\end{tabular}

c) Evaluations of novice nurses by the preceptors (Table 3): Preceptors who reported that skills of novice nurses are poor $(p<.05)$, and those who have established a good relationship in communicating with the novice nurses showed statistically significant differences $(p<.01)$. The correlation coefficient between the evaluation of novice nurses by preceptors and the assertiveness of those who reported that skills of novice nurses are poor was $r=0.11(p<.05)$, and that of those who reported to have established a good relationship in communicating with the novice nurses was $\mathrm{r}=0.12(p$ $<.01)$.

d) Self-evaluations of the preceptors (Table 3): Significant differences were found in the following items: thinking it worth instructing novice nurses, thinking oneself to be as valuable as others, making rapid decisions, and having confidence in nursing practices $(p<0.01)$. There were weak correlations between the self-evaluation of the preceptors and assertiveness: those who think it worth instructing novice nurses, $\mathrm{r}=0.19(p<.01)$; those who think themselves to be as valuable as others $\mathrm{r}=0.32(p<.01)$; those who report that they make rapid decisions, $\mathrm{r}=0.31(p<.01)$, and those who have confidence in their nursing, $\mathrm{r}=0.31(p<.01)$.

Working environment and assertiveness (Table 2): There were statistically significant differences in the following items: those who have superiors to consult with about the instruction of the novice nurses $(p<.05)$, those who are satisfied with the workplace $(p<.01)$, and those who report that they collaborate with staff in other occupations at the workplace $(p$ $<.01)$. Statistically significantly higher assertiveness was found in preceptors who have superiors to consult with about the instruction of the novice nurses $(p<.05)$. There were weak correlation coefficients between the environmental factors and assertiveness: those who are satisfied with the workplace, $\mathrm{r}=$ $0.147(p<.01)$; and those who report that they collaborate with other occupations at the workplace, $\mathrm{r}=0.188(p<.05)$.

e) Stress conditions and assertiveness (Table 3): There was a statistically significant difference between the assertiveness and the total burnout score of preceptors ( $p$ $<.01)$, here the correlation coefficient was $\mathrm{r}=-0.34(p<.01)$.

3) Results of the multivariate analysis (Table 4): Table 4 shows factors affecting assertiveness identified by the multiple regression analysis. We conducted a multiple linear regression analysis by selected variables (stepwise method) giving an adjusted coefficient of determination of 0.153 and a ratio of the explanatory variance $15.3 \%$.The results of the multiple regression analysis showed the influence in the participants who think they make rapid decisions $(\beta=0.230, p<.01)$, and who think themselves to be as valuable as others $(\beta=0.180, p$ $<.01)$ among the self-evaluations of the preceptors; and the total burnout scores $(\beta=-0.116, p<.05)$ among the stress conditions. The stronger the preceptors of novice nurses think that they make rapid decisions and that they are as valuable as others, they tend to have higher assertiveness, while those who have higher total burnout scores have lower assertiveness.

\section{DISCUSSION}

In this study we explored the factors related to, and affecting the assertiveness of preceptors of novice nurses in city and university hospitals with 300 or more beds in Japan, and conducted two cross-sectional studies (baseline survey and follow-up survey 8 months after the baseline survey) to verify the hypothesis. Further, in the longitudinal study, we conducted a prospective cohort study to verify the hypothesis. The 
characteristics of the participants in this study and the factors affecting assertiveness we investigated are discussed below.

\section{A. Characteristics of the participating hospitals and participants}

The participants in this study were 885 preceptors in charge of instructing novice nurses in city and university hospitals with 300 or more beds across Japan. Obtaining offers of cooperation from 37 hospitals, we conducted a prospective cohort study. Participants were 472 preceptors who were able to be followed with the prospective cohort study approach. The median age of the participants is 31 years, which is higher than that of the study of Yoshitomi et al., which investigated changes in preceptorship research $(198-2003)$, and reported ages as 24 to 27 years [4]. Although the result from the present study, of 31 year olds, may be considered to deal with older preceptors than previous studies, this difference may be because the study by Yoshitomi et al. was conducted under the framework of preceptor proposed by the Ministry of Health, Labour and Welfare [14] that nurses who would play a role of preceptors should be nurses in the second year of clinical experience or similar, nurses whose age is close to that of the novice nurses. In April 2010, to alleviate the burden on preceptors, the Ministry of Health, Labour and Welfare initiated a new nurse training framework, and since then, all nurses have been engaged in novice nurse training by a team of the whole ward, and we were unable to locate studies which systematically investigated the age of preceptors after the introduction of the new framework. For this reason, we have assumed that the age of preceptors of previous studies is similar to the participants of this study. Therefore, we consider that the participants here represent preceptors across Japan. The mean total assertiveness scores of participants here were -10.10 to -10.25 , and those of head nurses and supervisory nurses were -9.1 and -7.3 although these two nurse categories were excluded from the analysis in this study. Suzuki et al. measured assertiveness of novice nurses, head nurses, and supervisory nurses with the Japanese version of the Rathus Assertiveness Schedule (J-RAS) [15], and reported that the mean scores of the three groups were $-12.1,-3.1$, and -8.6 [16]. Although it is difficult to compare the results of the present study with those of previous studies, the score here is higher than that of previous studies for the novice nurses, and lower for the head nurses and supervisory nurses. Therefore, the assertiveness of preceptors may be higher than that of novice nurses, and lower than that of nurses assigned to managing positions.

\section{B. Factors affecting assertiveness by multiple linear regression analysis}

As a result of the multiple linear regression analysis in this study, the adjusted coefficient of determination was 0.153 . For the adjusted coefficient of determination, Murase et al. reported that there is much statistical noise present as confounding factors in social survey data, that results from social surveys are a model that is useful to be referred to when interpreting coefficients of determination if the coefficient of determination exceeds 0.20 , and that even if the value of the coefficient of determination is 0.10 or less, it is commonly regarded as an effective analysis if the F value of the whole model is
Table 4 Results of multiple linear regression analysis of preceptor assertiveness (Stepwise method)

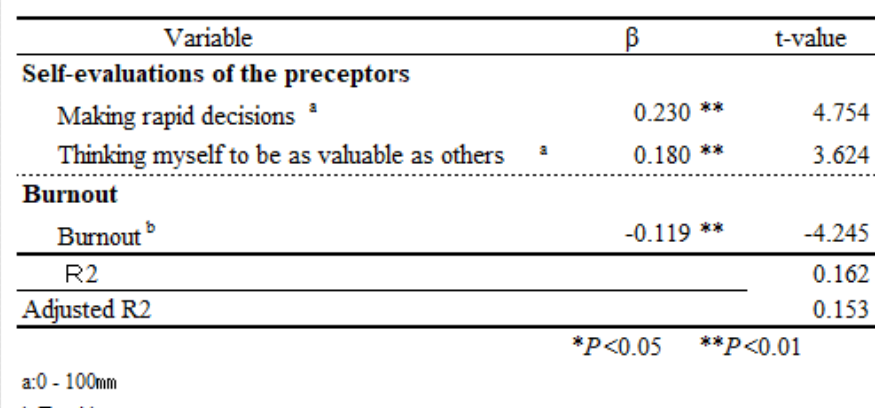

b:Total burnout score

statistically significant [18]. The present study is also a social survey, and the F value of the whole model of this survey was significant.

Further, the R2 in this study was low. The possible reason for this may be that there was not a sufficient number of explanatory variables available that had been used in previous studies. For example, there are a great number of studies using burnout as an objective variable, reporting factors related to and affecting assertiveness. However, this study is the first to identify the factors related to the assertiveness of preceptors using the J-RAS as an objective variable, and we were unable to locate studies that identify factors related to and affecting assertiveness systematically.

Factors affecting assertiveness as identified by the multiple linear regression analysis are discussed below.

1) Self-evaluation of preceptors and assertiveness: The stronger the preceptors of novice nurses report that they think they make rapid decisions and that they are as valuable as others, they tend to have higher assertiveness. Related to this result, Uchida [19], and Dodd [20] have reported the relationship between the decision skills and assertiveness of nurses. About practical skills and assertiveness of nurses, Lyndon [21] has reported that assertive communication behavior of nurses and practical nursing abilities are related. Kilks [10] has reported a relationship between the assertiveness of nurses and having confidence in the own professional skills. These are the results of the research with nurses, and in the present study that focuses on preceptors it was found that assertiveness is strongly related to having confidence in nursing practice.

For preceptors, having opportunities to think about the meaning of nursing such as holding case study meetings to discuss the nursing they provide everyday could be helping them to gain confidence in their nursing, leading to the improvements in assertiveness. It may also be expected that this confidence may strengthen the assertiveness and lead to the creation of an assertive relationship with novice nurses in the instruction. There were no studies that investigated the relationship between the assertiveness of preceptors and their thinking that they are as valuable as others. However, there are 
a number of studies that report the relationship between the self-esteem and assertiveness of nurses [22-24]. Lawton and Hiraki reported that nurses who have confidence in their nursing show higher assertiveness [21, 22]. Fujita et al. reported that the assertiveness among nurses is a factor that improves self-esteem [23]. Saisaka et al. suggest that selfesteem is an important factor to improve assertiveness among nurses [24]. Although these are studies of nurses, they suggest the possibility that the assertiveness of preceptors is strongly related to preceptors thinking positively about themselves. This makes it possible to infer that thinking positively about themselves here is an important factor leading to assertive self-expression.

2) Stress conditions and assertiveness: Preceptors with lower burnout risk reported higher assertiveness. Suzuki et al. [25], Suzuki [26], Maruyama et al. [27], Osato [7], and Sakai et al. [28] investigated the relationship between burnout and assertiveness, and reported assertiveness as a factor affecting burnout, suggesting that nurses with lower assertiveness could tend to develop burnout. Suzuki et al. has reported that the low assertiveness score of novice nurses may be a predictor for burnout risk [25]. Maruyama et al. [27] investigated novice nurses and has reported that working in the preferred section (ward) and improvement of assertiveness contributes to a decrease in the burnout risk one year after the commencement of employment. The results in the present study suggest that preceptors with lower burnout risk may have a better ability to express opinions in an assertive manner, and that assertiveness and burnout may be inter-related.

Osato et al. [7] has reported that nurses who have better assertive communication skills are able to alleviate psychological conflicts and stress, making the mental health of the nurses improve, and inter-personal relations less conflicted. However, if the assertiveness of preceptors is low, and conditions where the preceptors easily develop burnout continue, such preceptors may not be able to establish positive relationships with novice nurses [29]. Also, because interpersonal relationships involve interactions, non-assertive behaviors may be perceived by novice nurses, making the novice nurses more nervous [30]. For this reason, it is important for preceptors to work to relieve stresses in the nursing practices and in the interactions with novice nurses, and taking part in assertiveness training will be an effective approach to raise the level of assertiveness of preceptors [22]. Considering the matters discussed above, it would be important for nursing administrators to effect improvements in the working environment that makes it easier for colleagues and superiors to provide preceptors with positive feedback.

\section{Limitations of the present study and issues to be addressed in future studies}

There are some studies that have investigated the relationship between assertiveness and nurses. However, only few studies looked at preceptors, and factors affecting their assertiveness, which is the communication skill in the everyday work. This study is the first to examine the assertiveness of preceptors who instruct novice nurses and the factors affecting their assertiveness. As a result of the multiple linear regression analysis in this study, the adjusted coefficient of determination was 0.153 . Due to the scarcity of the studies, factors affecting the assertiveness, which are explanatory variables, have yet to be reported. This may have influenced the low explanatory rate. Further studies will be necessary to investigate factors related to the assertiveness of preceptors.

\section{CONCLUSIONS}

1) It can be inferred that the assertiveness of preceptors is higher than that of novice nurses measured by the J-RAS used in this study, and lower than that of administrative nurses. It is also possible that age and years of clinical experience may not be the factors affecting the assertiveness because the multivariate analysis did not show the relationship between the assertiveness and these two items although the bivariate analyses showed significant differences.

2) In a hypothesis testing to examine factors affecting the assertiveness of preceptors, the following variables were chosen:

a) The assertiveness of preceptors was higher among participants who evaluated themselves positively, thinking that 'they make rapid decisions', and that 'they are as valuable as others'.

b) The assertiveness of preceptors was lower among participants 'with high total burnout scores'. These findings suggest that a positive self-evaluation improves assertiveness and helps to prevent burnout.

\section{ACKNOWLEDGMENT}

We would like to thank all the nursing directors of the collaborating hospitals for their assistance with data collection. We also wish to thank all the nurses for participating in the present study.

\section{REFERENCES}

[1] Y. Hidaka, "Measurement and evaluation of how senior nurses establish relationships desired by new graduate nurses (Shinjin kangoshiga motomeru senpaikangoshino kakawari - kakawari shakudono sakuseito hyouka in Japanese)", Journal of Japan Society for Medical Education, vol. 46(1), pp. 43-51, 2014.

[2] Y. Oryu, N. Umezaki, \& Y. Shida, "The self-images as instructors held by preceptors when receiving novice nurses (Shinjin kangoshiwo murakeru puriseputa ga idaku jikono shidoushazou in Japanese). National defense medical journal, vol. 60(9,10), pp. 153-158, 2013

[3] S. Tomita, E. Suzuki and S. Nakazawa, "Factors and related to assertiveness among preceptors of novice nurses and their characteristics (Shinsotsu kangoshini kakawaru puriseutaano assathibunesuno kanren youin to sono tokucho in Japanese)", Journal of Japan Health Medicine Association, vol. 36(3), pp. 139-140, 2017

[4] M. Yoshitomi \& N. Funashima, "Role model behaviors of preceptor for new graduate nurses (Pureseputato shinjin kangoshino souzo kouini kansuru kenkyu in Japanese)", Japan Academic Society of Nursing Education, vol. 5(2), pp. 12-38, 2006.

[5] S. Tomita, E. Suzuki and I. Itomine, "Factors related to assertiveness among preceptors of novice nurses (Shinsotsu kangoshini kakawaru puriseutaano assathibunesuto sono kanren youin in Japanese)", 
Proceedings of the $34^{\text {th }}$ Academic Conference Japan Academy of Nursing Science, p. 585, 2014.

[6] Y. Tamai, T. Kageyama, \& H. Maeda, "Identity expressed in the behaviors of senior nurses toward novice nurses - Focusing on assertive elements (Shinjin kangoshini taisuru senpai kangoshino jiko hyougen taidoni tsuite in Japanese)", The Japanese Journal of Mental Health, vol. 22(2), pp. 66-79, 2007.

[7] M. Osato, M. Shitara, T.Yamazaki, \& Y. Ishizaki, "Connection with Assertion and the Occupational Stress of the Psychiatric Nurses (Seishinka naasuno asaashonto shokuba sutoresutono kanren in Japanese)", Journal of Japan Academy of Psychiatric and Mental Health Nursing, vol. 19(1), pp.155-160, 2010.

[8] E. Suzuki, Y. Kanoya, K.Takeishi, \& C. Sato, "Assertiveness affecting burnout of novice at university hospitals", Japan Journal of Nursing Science, vol. 3, pp.93-105, 2006.

[9] M. Fudo, "Guide to establish assertive relationships and change the behaviors of others - Ensuring behaviors confirmed by pointing and voicing - (Asaathibuna ningenkankeiwo kouchikushi tashano koudouwo henyousaseruniha - yubisashi koshodeno kakunin koudouno shuchiwo tooshite in Japanese)", Nagoya Geriatric Medicine, vol. 34, pp. 35-37, 2008.

[10] S. Kilkus, "Assertiveness among professional nurse", Journal of Advanced-Nursing, vol.18(8), pp. 1324-1330, 1993.

[11] E. Suzuki, T. Azuma T, A. Maruyama A., M. Saito \& Y. Takayama, Situations and reasons novice nurses cannot be assertive toward their senior nurses (Shinsotsu kangoshiga senpaikangoshini taishite asaathibuni narenai jokyoto sono riyuu in Japanese)", The Journal of the Japan Academy of Nursing Administration and Policies, vol. 18(1), pp. 36-46, 2014.

[12] Y. Yamanaka, \& S. Sasahara, "Efforts of improvements in communication among staff - through assertion training (Sutaffukan komyunikeishon kaizenheno torikumi in Japanese). The Japanese Psychiatric Nursing Society, vol. 56(2), pp. 296-300, 2014.

[13] R. E. Alberti \& M. L.Emmons (1986). /Translated by K. Sugawara, "Your perfect right: a guide to assertive behavior: Training for selfexpression”, Tokyo: Tokyo Tosho Co., Ltd. Tokyo, pp. 31-32, 1986.

[14] Ministry of Health, Labor and Welfare, "Report of workshop for novice nurse training (Shinjin kangoshokuin kenshuni kansuru kentoukai houkokusho in Japanese)", pp. 1-4, 2009.

[15] E. Suzuki, M. Saito, A. Maruyama, T. Azuma, T. Katsuki, \& C. Sato, "Verification of reliability and validity of the Japanese Version of the Rathus Assertiveness Schedule (J-RAS) among executive nurses (Kango Kanrishano Nihongoban, Rathus assertiveness schedule noshinraiseito datouseino kensho in Japanese)", Japanese journal of human sciences of health-social services", vol. 14(1), pp.33-41, 2007.

[16] E. Suzuki E, Y. Kanoya, S. Ishida, T. Katsuki, \& C. Sato, "The development of the Japanese version of the Rathus assertiveness schedule (Nihongoban, Rathus assertiveness schedule kaihatsuni kansuru kenkyu in Japanese)", Japanese journal of human sciences of health-social services, vol. 10(2), pp. 19-29, 2007.
[17] K. Azumaguchi, Y. Morikawa, K. Miura, M. Nishijo, M. Tabata, \& K. Yoshita, "The development of the Japanese version of the Maslach Burnout Inventory and the examination of the factor structure (Nihonban MBI nosakuseito inshi kouzouno kentou in Japanese)", Japanese journal of hygiene, vol. 53(2), pp. 447-455, 1998.

[18] Y. Murase, H. Takada, \& A. Hirose, "Multivariate analysis with SPSS (SPSS niyoru tahenryo kaiseki in Japanese)," Ohmsha, Tokyo, p. 173, 2007.

[19] K. Uchida, \& Y. Shimada, "A literature review on new graduate nurse turnover in Japan", Journal of health sciences of mind and body, vol. 11(1),pp.18-23, 2015.

[20] S. J. Dodd, B. S. Jansson, K. Brown-Saltzman, M. Shirk, \& K. Wunch, "Expanding nurses'-participation in ethics: an empirical examination of ethical activism and ethical assertiveness", Nurs Ethics, VOL. 11(1),PP. 15-27, 2004.

[21] S. Lawton S, \& F. Stewart, "Assertiveness: making yourself heard in district nursing”, Br J Community Nurs, vol.10(6), pp. 281-283, 2005.

[22] S. Hiraki, “Assertiveness training - For a bright <Self-expression> (Asaashon toreiningu - sawayakana <jiko hyougen> notameni in Japanese)", $2^{\text {nd }}$ ed., Nisseiken, Inc., Kanekoshobo, Tokyo, pp. 48-50, 2012 .

[23] K. Takimoto, M. Michihiro, Y. Kawano, \& K. Fujita, "Conditions and factors affecting assertiveness of nurses in clinical settings (Iryogenba niokeru kangoshino asaathibu nouryokuno jittaito youin in Japanese)", Journal of Nursing Sciences of Ube Frontier University, vol. 1(1), pp. 59-68, 2008.

[24] Y. Saisaka, M. Matoba, K. Izawa K, A. Tominaga, R. Nishimoto, "Survey of assertive communication in university hospitals (Daigakubyoin niokeru asaathibu komyunikeishon jittai chosa in Japanese)", The Journal of the Japan Academy of Nursing Administration and Policies, vol. 32, pp. 276-278, 2001.

[25] E. Suzuki, I. Itomine, \& M. Saito, "Factors affecting the turnover of novice nurse at university hospitals - A two year longitudinal study- ", Japan Journal of Nursing Science, vol. 5(1), pp. 9-21, 2008.

[26] E. Suzuki, Y. Kanoya, \& K. Kitaoka (Higashiguchi), "Workplace Environment, Assertiveness and Burnout risk among Novice Nurses in University Hospitals", Japanese journal of nursing research, 28(2), pp. 89-99, 2005.

[27] A. Maruyama, \& E. Suzuki, "Characteistics of novice nurses in pediatric wards at university hospitals", The journal of the Japan Academy of Nursing Administration and Policies, vol. 13(1), pp. 92-99, 2009.

[28] I. Sakai, H. Mitsuhashi, \& C. Mori, "Relationship between selfawareness and the awareness of others for nurses in psychiatry wards (in Japanese)", Psychiatric Mental Health Nursing, vol. 35, pp. 112-115, 2004.

[29] H. Seki, "Corresponds to the revised laws for public health nurses and midwives - Improvement of training for newly graduated nursing staff, Medical business information report, Sekisouken, pp. 1-12, 2011.

[30] T. Okawa, Y. Muroi, Y. Ikeda, \& et al. "Novice nurses' recognition on the supports that receive from senior nurses (in Japanese)" Bulletin of Nursing sciences, Fukushima Medical University, vol.6, pp.9-23, 2004. 


\section{AUTORS PROFILE}

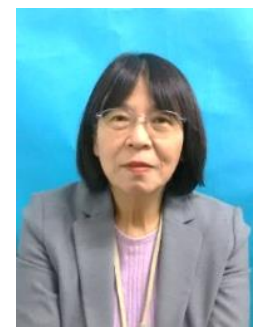

Ms Sachie Tomita, completed doctoral degree at the International Medical Welfare University Graduate School. She currently professor Fundamental Nursing at Faculty of Health \& Medical care, Saitama Medical University.

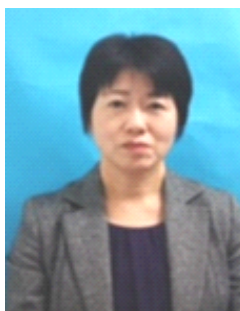

Ms. Hiromi Yokoyama, After working in a hospital for 11 years she worked as a I completed my master's degree at the Saitama Medical University Graduate School. She currently teaches Fundamental Nursing at Faculty of Health \& Medical care, Saitama Medical University.

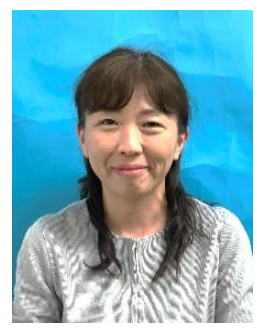

Ms. Kyoko Chiba, After working in a hospital for 5 years she worked as a I completed my master's degree at the Saitama Medical University Graduate School. She currently teaches Fundamental Nursing at Faculty of Health \& Medical care, Saitama Medical University.

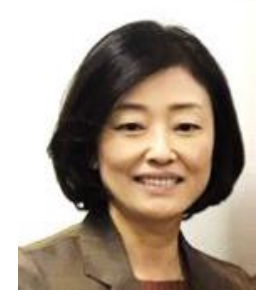

\section{Assistant Professor Takae Machida} master's degree of Nursing management. SAITAMA MEDICAL UNIVERSITY,Japan

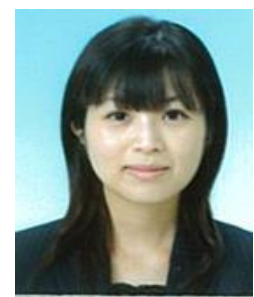

Ms. Saori Nakazawa, After working in a hospital for 13 years she worked as a I completed my master's degree at the International Medical Welfare University Graduate School. She currently teaches Fundamental Nursing at Faculty of Health \& Medical care, Saitama Medical University.

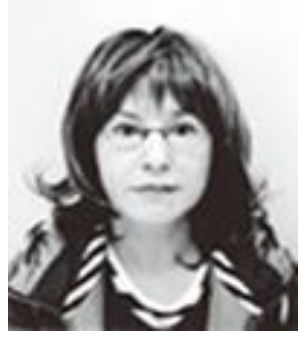

Ms. Eiko Suzuki, obtained her Phd of Science in Nursing at Tokyo Medical and Dental University. She currently professor at International University of Health and Welfare Graduate School. 